\title{
Fish Passages in South America
}

\author{
Preface
}

Nowadays, reservoirs constitute a non-dissociable characteristic of the landscape in South American river basins. For some important Brazilian rivers, the natural slope has been fragmented by the succession of dams and artificial lakes, with a huge reduction in lotic stretches. One of the most obvious impacts resulting from the cascade of dams is on migratory fish populations. The interruption of migration routes separates the environments of initial development, spawning and growth, and this is, in large part, responsible for the virtual disappearance of large migrants, as in the case of the upper stretches of the Paraná River. These impacts have social and economic repercussions, because migratory species include almost all large-sized and excellent flesh fishes, with thousands of families depending on them to sustain their lives.

In South America, especially in Brazil, management policies related to minimizing reservoir impacts were historically related to stocking (construction of hatcheries), fishery control (enforcement) and fish translocation (fish passages), usually constrained by law. Unfortunately, most of these actions failed, mainly because they were based on poor technical and scientific information and had unclear purposes. The low fishery yield in reservoirs located in South and South-East Brazil, with a sharp reduction of migratory species, clearly indicates that these management actions were, at best, not satisfactory.

Fish passages, the subject of this Neotropical Ichthyology (NI) issue, are generally conceived to reestablish connectivity among critical habitats for migratory species, thus mitigating the impacts of the blockage on migration routes by dams. Therefore, the efficiency of these passages could be defined as the proportion of fish that passes through them, or in a broader view, the role of passages is to make it possible to have sustainable fish populations. In some situations, the ascent of fish could be considered for some species, including non migratory, to promote genetic improvements. However, if this management tool is to be meaningful for the conservation of fish species, it must provide a fully permeable connection and assure both upward and downward movements.

It was expected that efficient fish passages would lead to the maintenance of fish populations above reservoirs, without damaging downstream populations. However, this does not appear to be a simple task, as seen so far. The South American freshwater fish fauna is the most diverse in the world, with at least 4,500 valid species ( 15 to $20 \%$ migratory), but most of them have yet to be studied.

Since 1911, when the first fish ladder was completed in Brazil (Itaipava Dam, Pardo River), we lost several opportunities to learn about the operation of fish passages. After a century and dozens of fish ladders constructed, no monitoring or study has been performed on the fish that overcome the obstacle and reach the reservoir and upper stretches or of the necessary downward movements of spawners and their offspring to the stretches below dams. Up to few years ago, most publications related to fish passages was in the form of internal reports within power companies or other forms of gray literature. Moreover, these publications only considered the fish present in the fish passage, with no information about upward and downward movements.

Considering these aspects, the "International Symposium on Fish Passages in South America" (ISFPSA) held at the "Universidade Federal de Lavras" (Minas Gerais State, Brazil) is extremely opportune for discussing these problems, and this issue of NI, a peer-reviewed journal, is the perfect venue to publish the valuable information presented during the meeting.

In conclusion, the issue of NI and the ISFPSA make a huge contribution to the debate and dissemination of the information about this theme.

The editors 